\title{
The handbook for standardized field and laboratory measurements in terrestrial climate change experiments and observational studies (ClimEx)
}

\author{
Aud H. Halbritter ${ }^{1}$ (D) | Hans J. De Boeck ${ }^{2}$ (D) | Amy E. Eycott ${ }^{3,4}$ (D) | Sabine Reinsch \\ David A. Robinson ${ }^{5}$ (D) | Sara Vicca ${ }^{2}$ (D) | Bernd Berauer ${ }^{6}$ iD | Casper T. Christiansen \\ Marc Estiarte $^{8,9}$ (D) | José M. Grünzweig ${ }^{10}$ ｜ Ragnhild Gya ${ }^{1}$ | Karin Hansen ${ }^{11,12}$ | \\ Anke Jentsch ${ }^{6}$ (D) | Hanna Lee ${ }^{7}$ (D) | Sune Linder ${ }^{13}$ (D) | John Marshall ${ }^{14}$ | \\ Josep Peñuelas $^{8,9}$ (D) | Inger Kappel Schmidt ${ }^{15}$ (D) | Ellen Stuart-Haëntjens ${ }^{16}$ (D) | \\ Peter Wilfahrt $^{6}$ (D) | the ClimMani Working Group* | Vigdis Vandvik ${ }^{1}$ iD \\ ${ }^{1}$ Department of Biological Sciences and Bjerknes Centre for Climate Research, University of Bergen, Bergen, Norway; ${ }^{2}$ Department of Biology, Centre of \\ Excellence PLECO (Plants and Ecosystems), Universiteit Antwerpen, Wilrijk, Belgium; ${ }^{3}$ Department of Biological Sciences, University of Bergen, Bergen, \\ Norway; ${ }^{4}$ Faculty of Biosciences and Aquaculture, Nord University, Steinkjer, Norway; ${ }^{5}$ Centre for Ecology \& Hydrology, Environment Centre Wales, Bangor, \\ UK; ${ }^{6}$ Department of Disturbance Ecology, University of Bayreuth, Bayreuth, Germany; ${ }^{7}$ NORCE Norwegian Research Centre and Bjerknes Centre for Climate \\ Research, Bergen, Norway; ${ }^{8} \mathrm{CSIC}$, Global Ecology Unit CREAF-CSIC-UAB, Bellaterra, Spain; ${ }^{9} \mathrm{CREAF}$, Vallès, Spain; ${ }^{10}$ Institute of Plant Sciences and Genetics in \\ Agriculture, The Hebrew University of Jerusalem, Rehovot, Israel; ${ }^{11}$ Swedish Environmental Protection Agency, Stockholm, Sweden; ${ }^{12}$ Swedish Environmental \\ Research Institute IVL, Stockholm, Sweden; ${ }^{13}$ Southern Swedish Forest Research Centre, Swedish University of Agricultural Sciences, Alnarp, Sweden; \\ ${ }^{14}$ Department of Forest Ecology and Management, Swedish University of Agricultural Sciences, Umeå, Sweden; ${ }^{15}$ Department of Geosciences and Natural \\ Resource Management, University of Copenhagen, Frederiksberg, Denmark and ${ }^{16}$ Department of Biology, Virginia Commonwealth University, Richmond, VA, \\ USA
}

\section{Correspondence}

Aud H. Halbritter

Email: aud.halbritter@uib.no

Vigdis Vandvik

Email: vigdis.vandvik@uib.no

Funding information

ClimMani COST Action (2014-2018), Grant/

Award Number: ES1308

Handling Editor: Robert Freckleton

\section{Abstract}

1. Climate change is a world-wide threat to biodiversity and ecosystem structure, functioning and services. To understand the underlying drivers and mechanisms, and to predict the consequences for nature and people, we urgently need better understanding of the direction and magnitude of climate change impacts across the soil-plant-atmosphere continuum. An increasing number of climate change studies are creating new opportunities for meaningful and high-quality generalizations and improved process understanding. However, significant challenges exist related to data availability and/or compatibility across studies, compromising opportunities for data re-use, synthesis and upscaling. Many of these challenges relate to a lack of an established 'best practice' for measuring key impacts and responses. This restrains our current understanding of complex processes and mechanisms in terrestrial ecosystems related to climate change.

2. To overcome these challenges, we collected best-practice methods emerging from major ecological research networks and experiments, as synthesized by 115

${ }^{*}$ ClimMani Working Group authors and their affiliations are listed in the appendix.

This is an open access article under the terms of the Creative Commons Attribution License, which permits use, distribution and reproduction in any medium, provided the original work is properly cited.

(c) 2019 The Authors. Methods in Ecology and Evolution published by John Wiley \& Sons Ltd on behalf of British Ecological Society. 
experts from across a wide range of scientific disciplines. Our handbook contains guidance on the selection of response variables for different purposes, protocols for standardized measurements of 66 such response variables and advice on data management. Specifically, we recommend a minimum subset of variables that should be collected in all climate change studies to allow data re-use and synthesis, and give guidance on additional variables critical for different types of synthesis and upscaling. The goal of this community effort is to facilitate awareness of the importance and broader application of standardized methods to promote data re-use, availability, compatibility and transparency. We envision improved research practices that will increase returns on investments in individual research projects, facilitate second-order research outputs and create opportunities for collaboration across scientific communities. Ultimately, this should significantly improve the quality and impact of the science, which is required to fulfil society's needs in a changing world.

\section{KEYWORDS}

best practice, coordinated experiments, data management and documentation, ecosystem, experimental macroecology, methodology, open science, vegetation

\section{1 | INTRODUCTION}

Climate change is an increasing threat to biodiversity and ecosystem functions and services world-wide (IPBES, 2019; Pacifici et al., 2015; Schuur et al., 2015). Numerous studies, including experiments, long-term monitoring, resampling of historic data and various kinds of space-for-time approaches, have been and are being conducted. Such studies address climate and other global change-related questions for various players and processes in ecosystems across the soil-plant-atmosphere continuum. Plants are key players in our ecosystems: they make up the majority of biomass globally, are the main source of photosynthetically fixed carbon and serve as habitat, food sources and hosts for other organismal groups, while also competing with them for resources (Bar-On, Phillips, \& Milo, 2018; Fanin et al., 2019). Plants interact with other plants, microbes, invertebrates and other organisms in multiple ways and on different trophic levels (e.g. decomposers, mutualists, pathogens, herbivores, predators). Together, they play a major role in controlling important terrestrial ecosystem processes such as carbon and nutrient cycling (Clemmensen et al., 2013). Improved understanding of the magnitude of climate change impacts, the underlying drivers and mechanisms and the ecological consequences at the individual, population, community and ecosystem scales across the soil-plantcontinuum, with a focus on first-order plant-animal interactions in detritivore and herbivore food web is urgently needed.

In climate change research, the most common empirical approaches include manipulative experiments sensu stricto (Elmendorf et al., 2012; Emmett et al., 2004; Guittar, Goldberg, Klanderud, Telford, \& Vandvik, 2016; Wu, Dijkstra, Koch, Penuelas, \& Hungate, 2011) and natural experiments that explicitly contrast or compare different climates through space (i.e. climate gradient studies; Halbritter, Alexander, Edwards, \& Billeter, 2013; Olsen, Töpper, Skarpaas, Vandvik, \& Klanderud, 2016) and time (i.e. monitoring or resampling; Fitter \& Fitter, 2002; Steinbauer et al., 2018). Climate change experiments sensu stricto are particularly useful in establishing cause-and-effect relationships, disentangling the effects of and interactions between different drivers and understanding underlying processes (De Boeck et al., 2015; Fraser et al., 2013). Natural experiments are useful to detect processes on large spatial and temporal scales, related to evolutionary processes and equilibria, and they also avoid experimental limitations and side effects. Hereafter, we refer to these collectively as 'climate change studies' sensu lato (if not otherwise specified).

As the number of such climate change studies is quickly increasing, new opportunities for meta-analyses and syntheses are emerging to explore broad-scale patterns and context dependencies in effects, responses and processes, as well as for model development and evaluation. However, there are major challenges for meaningful and high-quality syntheses, including geographic and climatic biases in the available studies (Beier et al., 2012; Vicca et al., 2014), a lack of coordinated measurements and standardized protocols (Denny et al., 2014; Firbank et al., 2017; Vicca, Gilgen, et al., 2012) and a lack of basic and well-structured study information (i.e. covariates, metadata) needed for comparisons (Gerstner et al., 2017; Haddaway \& Verhoeven, 2015). Similarly, model-experiment interactions are hampered by methodological inconsistencies across experiments, and by the lack of specific ancillary data to characterize sites and experimental treatments (Medlyn et al., 2015).

The majority of climate change studies are local or regional, and single- to multiple-site studies that are designed to address 
specific research questions. As a consequence, these studies often have unique experimental and sampling designs (e.g. Countryside survey, Emmett et al., 2010; ExpeEr, Bertora et al., 2013; INCREASE, Schmidt et al., 2014). Individual research projects and networks invest considerable resources in collecting data for a number of environmental and biotic variables and in developing protocols for field measurements. This leads to a diversity of similar but not quite identical protocols, and hence to a diversity of ways to measure and quantify the same underlying effects and responses. While some of this variability may be due to good scientific reasons, protocol selection is often based on traditions and habits. This methodological diversity can hinder backward compatibility, and thus, syntheses across studies, for example due to incompatible quantification of treatment effects, lack of necessary covariates or response variables, and/or incompatible scale or units of measurements (Estiarte et al., 2016; Lu et al., 2013; Vicca, Gilgen, et al., 2012). These issues largely stem from using a diversity of protocols, and we refer to this as the 'data compatibility filter' (Figure 1). Another issue that may hinder syntheses and meta-analyses is when key information is not available from the original studies. Data, covariates, metadata and detailed methodological information that are critical for the synthesis step may not be necessary for first-order publications and are hence not reported, structured well or stored in an accessible location and format. We refer to this issue as the 'data availability filter' (Figure 1), which is increasingly recognized in the scientific community and is, in part, addressed in recent guidelines on data management and open science practices (e.g. British Ecological Society, 2017; Nosek et al., 2015; and see protocol 1.5). Together, the data compatibility filter and the data availability filter significantly compromise second-order research outputs such as data re-use, synthesis and upscaling (Figure 1).

One way to address these challenges is through 'coordinated and distributed experiments' (Fraser et al., 2013; Luo et al., 2011; Figure 1), exemplified by the DroughtNet (Knapp et al., 2017), ITEX (Arft et al., 1999), NutNet (Borer et al., 2014), INCREASE (Schmidt et al., 2014) and Tea Bag Index network (Keuskamp, Dingemans, Lehtinen, Sarneel, \& Hefting, 2013). Similarly, broad-scale, long-term or repeated observational monitoring can be used, such as resampling studies (Steinbauer et al., 2018; Verheyen et al., 2016) or national phenological networks (Defila \& Clot, 2001; Denny et al., 2014). An alternative to such formalized networks is to facilitate coordination and standardization of methods and sampling protocols across studies more generally (Figure 1). The handbook for plant trait measurements is an excellent example of the latter approach; a collection of standardized, documented, stateof-the-art protocols for trait-based plant ecological research, providing

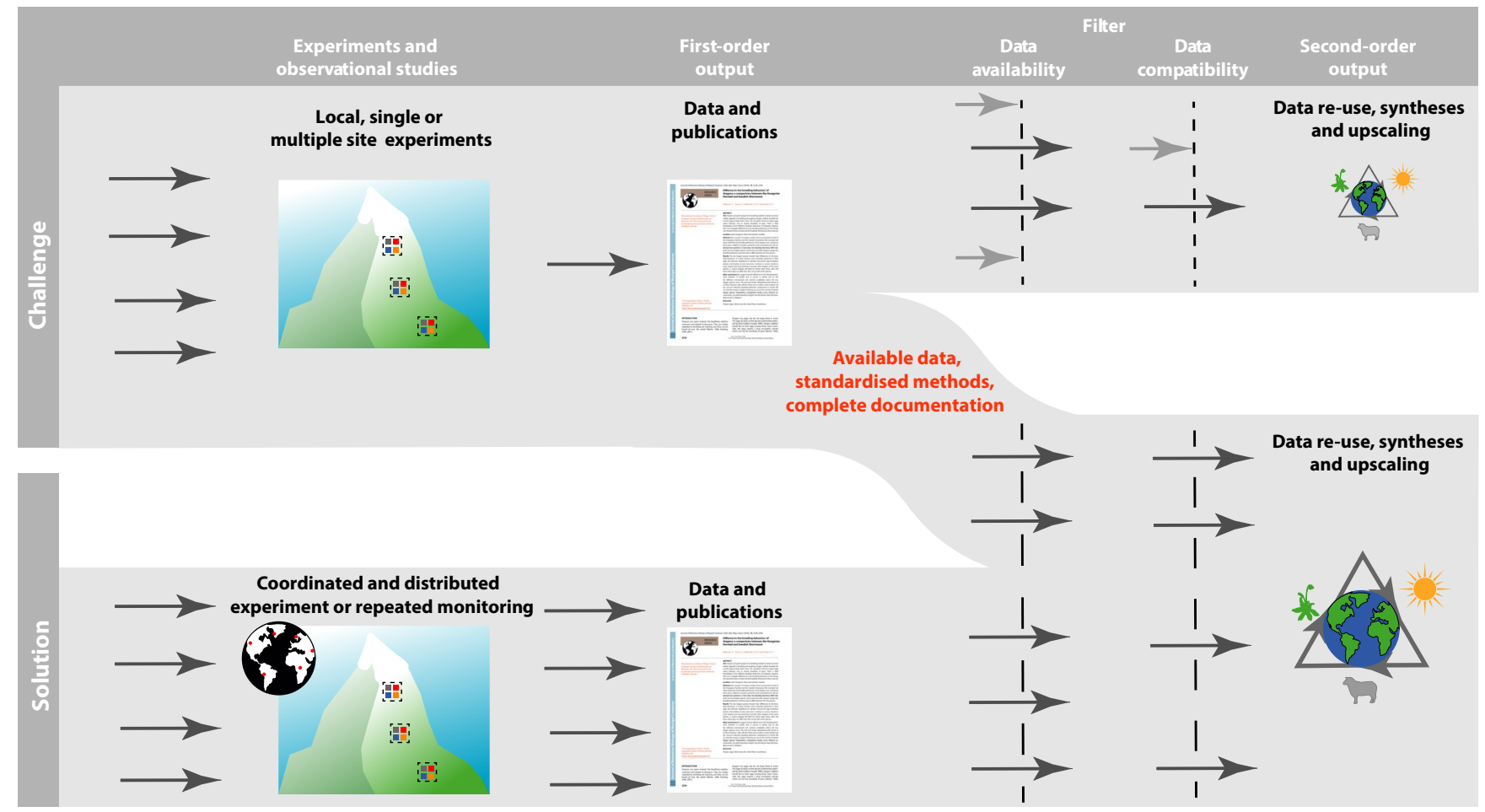

FIGURE 1 Challenges and solutions to the integration of information from first-order outputs of individual experiments or observational studies (i.e. the original data and publications) to second-order research outputs resulting from, for example meta-analyses, reviews and modelling (i.e. data re-use, synthesis and upscaling). The figure illustrates the major challenges to achieve such second-order outputs, summarized as two filters (dashed lines) relating to data availability and data compatibility across studies. Two general approaches to solve these challenges exist; either using formally coordinated and distributed experiments or using standardized methods, sampling protocols and reporting across individual and independent studies. The aim of this paper is to contribute to the latter approach by offering guidance on selection of response variables, protocols for standardized measurements of these variables and advice on data reporting and management in climate change studies 
general methodological advice on how to select and measure traits, independent of the particularities of the individual experiments or study (Cornelissen et al., 2003; Pérez-Harguindeguy et al., 2013). This handbook has become a key resource for trait-based research as it has been hugely important in stimulating the use of standardized methods while at the same time providing an easily available resource for new researchers in the field. Its potential is evident from its high impact world-wide (the two editions of the handbook have been cited over 1,700 times in Web of Science to date, September 2019). Other similar efforts exist like the web resource PrometheusWiki, a handbook for standardized physiological protocols (Sack et al., 2010), or the International Biological Program Handbooks (e.g. Milner \& Elfyn Hughes, 1968), as well as national or community standards such as the UK Countryside survey (Emmett et al., 2010) or the UK Environmental Change Network (Sier \& Monteith, 2016).

The aim of this paper was to provide a handbook (ClimEx) of standardized field and laboratory methods across the soil-plant-atmosphere continuum applicable to a broad range of terrestrial ecosystem climate change studies (including both experiments and plot-based temporal and spatial gradient studies) world-wide. Because of their dominance in terrestrial ecosystems (Bar-On et al., 2018), we focus mainly on plant communities and the other organisms with which

\section{BOX 1 ClimMani and the protocol writing team}

The EU Cost Action ClimMani (2014-2018) focussed on building and strengthening the experimental climate change research community. Key goals of this Action were to provide guidelines for best experimental practices, and to advance experiment-data-model interactions. ClimMani therefore set out to develop and promote common protocols as a community effort to guide future measurements and experiments, and to improve future inter-site comparisons, meta-analyses and model-experiment interactions.

In March 2017, 26 ClimMani members met for a workshop and initiated the collection of measurement protocols in climate change studies. The structure and outline for the project was developed, and leaders for the five chapters appointed. Researchers were identified that could lead protocols based on their scientific expertise. In total, the protocol writing team consisted of 85 authors, who wrote the protocols based on their expert knowledge and existing protocols in the literature. In a second round, 50 experts reviewed the protocols, after which the authors finalized the protocols by the end of 2017. A second workshop was organized in January 2018 to finalize and harmonize all protocols and agree on data presentation. In total, 115 scientists from 21 countries on four continents were involved. they interact. We discuss a variety of organisms (i.e. microbes, fungi, invertebrates and first-order plant-animal interactions) where the connection to vegetation and ecosystem functioning is apparent. Through a community effort by experts across scientific disciplines (Box 1), we provide a comprehensive collection of state-of-the-art methods and sampling protocols on key variables of relevance for terrestrial climate change research (Table 1).

The protocols are grouped into five chapters: site characteristics and data management, carbon and nutrient cycling, water cycling, species and interactions, and stress physiology. In each protocol, we describe which response variables should be measured broadly across studies to facilitate data re-use, synthesis and upscaling, using a Gold standard (if possible) and, if applicable, we offer minimal requirement Bronze standards. We discuss Special cases, emerging issues and challenges that address adaptations needed for specific systems or situations and new methods under development. Finally, we give guidance on additional variables that should be measured more widely to improve inter-site and inter-study comparisons and model-experiment interactions.

Our intention is that the ClimEx handbook will be widely used and will stimulate standardized data collection and collaboration between projects within and across sub-disciplines. We acknowledge that different projects may have different specific needs and resources available, and therefore propose a 'minimal set' of variables and practices that, if more widely applied, would significantly increase each individual study's potential contribution to second-order outputs. Many of the methods described in this handbook are also applicable more generally in ecosystem ecology and for other global-change drivers (e.g. nitrogen deposition, invasion, pollution, land-use change). Where relevant, this is indicated in the protocols.

\section{2 | MATERIALS AND METHODS - A USER'S GUIDE}

\subsection{How were the protocols produced and assessed?}

We collected a large number of protocols from major terrestrial climate change experiments; ITEX, DroughtNet and NutNet to name a few, and complemented these with literature on methodology, method descriptions from publications and protocols from our own projects (see the appendix for full reference lists). From these sources, we extracted a list of response variables that are relevant and commonly used in terrestrial climate change research (Table 1). A core group outlined the writing process, the relevant response variables, the protocol structure and the final editing, while expert teams on each topic wrote the protocols (Box 1).

We focussed on variables that are relevant for understanding climate change impacts on the biodiversity and functioning of the soilplant-atmosphere continuum, and/or which are particularly useful for data re-use, synthesis and upscaling. We do not comprehensively 
cover plant functional traits as these are already extensively covered in the New handbook for standardised measurement of plant functional traits worldwide by Pérez-Harguindeguy et al. (2013), but provide a motivation and overview of relevant traits (see Chapter S4), and otherwise refer to this source.

\subsection{Content and structure of the protocols}

For each protocol, we provide a short overview of the equipment and running costs, installation and maintenance effort, knowledgeneeds and the type of measurements conducted (Table 1). Note that this overview is to a certain extent country-, habitat- and project-dependent (i.e. costs differ between countries, knowledgeneeds for species identification might differ between a rainforest and a temperate bog). We give a short summary of the ecological background and its relevance to terrestrial climate change studies. We succinctly describe What and how to measure, providing sufficient detail to ensure reproducibility, and provide a reference list with more extensive literature on each method. We describe a Gold standard, that is the optimal measurement irrespective of economic, technical and practical constraints, and (if applicable) a Bronze standard, that is the minimal requirement for data of adequate quality, which can be advisable in specific situations. In the section on Special cases, emerging issues and challenges, we explain how the method can be adapted in specific cases and provide guidance on relevant challenges and opportunities. We further provide an extensive list of key references on the underlying theories, assumptions and applications of each method in the section on Theory, significance and large datasets, as well as under More on methods and existing protocols. These references may be especially useful for students, early-career scientists or research teams getting started in setting up new studies, and more generally for readers interested in exploring the wider literature related to a specific ecological response variable. Each chapter is available as a separate supplement for easier handling, but we encourage the climate change research community to be aware of aspects of other chapters outside their own scientific expertise.

\section{3 | RESULTS - OVERVIEW OF THE HANDBOOK CONTENT}

We produced a collection of 66 protocols, describing response variables ranging from elements and organisms to the ecosystem scale, organized into five supporting information chapters (Table 1). All protocols can be found in the online Supporting Information to this paper. In addition, the protocols are also available online on the ClimEx handbook webpage (climexhandbook.w.uib.no). To ensure that the handbook will also be a useful resource for the community in the future, comments and suggestions for updating the protocols can be made via the webpage. These comments and suggestions will be assessed by the authors of this paper and every update will be tracked. The protocols should be cited as appendices to this paper, see individual protocols for details. In the following, we present a summary of these chapters, guidance on their use and examples of their relevance to climate change research.

\subsection{Chapter 1: Site characteristics and data management}

Systematic reporting of background information of the studied system, data analysis and results is necessary to ensure that studies are reproducible and to enable data syntheses and analyses across studies, meta-analyses, modelling and upscaling (Gerstner et al., 2017; Haddaway \& Verhoeven, 2015). Such information includes a basic site description, such as geographic location and abiotic and biotic properties, pre-experimental baseline conditions (e.g. climate, soil properties), basic methodological descriptions (e.g. sample size, timing, duration), a proper characterization of treatments and results (e.g. units, effect sizes), and well structured and documented data management. Surprisingly, this necessary basic information is often incomplete or missing in scientific publications (Hillebrand \& Gurevitch, 2013).

The site characteristics and data management chapter (Supporting Information S1) therefore describes which key site, study system, and study design variables and information should be collected, and how this information is best reported. We first give practical guidance on how to design and set up a climate change study that may serve multiple uses beyond the needs of the particular project. Then, we describe basic site description parameters (e.g. coordinates, elevation, land-use history, vegetation) and physical (e.g. soil horizon, pH), chemical (e.g. nutrient availability) and meteorological variables. Although some of this information may not directly relate to the particular research question or hypothesis of the original project, reporting all relevant information is essential as it puts studies in a larger context and is key to making data and results useful beyond the particular research for which they were designed.

Arguably, improved collection and reporting of background information about the sites and study systems are probably the largest benefit of this handbook in terms of opportunities for second-order outputs (Figure 1). At the same time, these data are non-focus variables in most studies and therefore typically have low priority. To stimulate systematic and standardized collection and reporting of key background variables, we therefore provide an overview of the most critical variables, both overall and specifically for different kinds of data re-use, synthesis and upscaling (Table 2). Here, we also indicate the spatial scale (plot/treatment/site) at which the different variables should preferably be collected for different opportunities of data reuse. The first 'minimum requirement' column in Table 2 lists variables that all climate change studies - regardless of research question and focus - should measure and report. Background data of particular relevance for specific kinds of second-order outputs (i.e. meta-analyses, community modelling, ecosystem modelling, spatial and temporal upscaling) are indicated in the other columns (also see discussion below). 


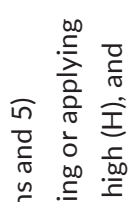

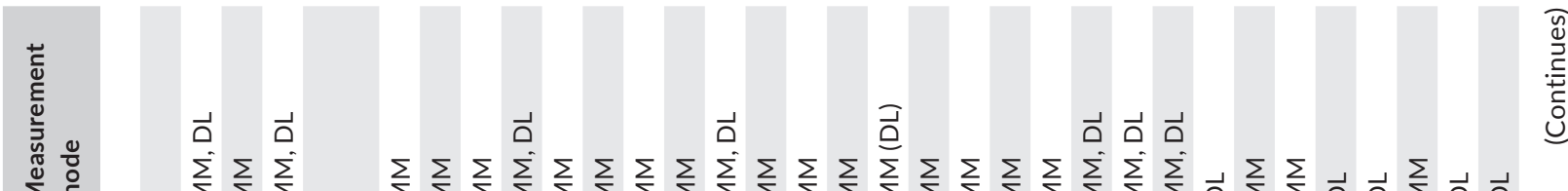

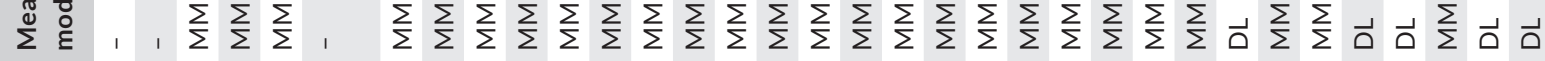

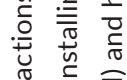

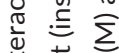

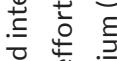
宁 离 बै 总 ज行

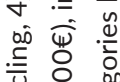
ปิ 离 䓠出 ल

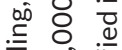
ปे + 음 类

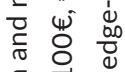
ㄷำ 离出政

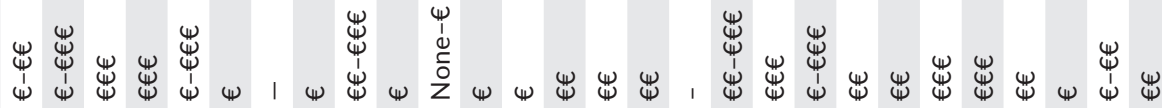

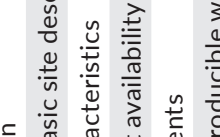

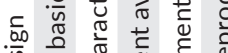

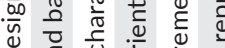

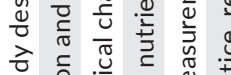

흔

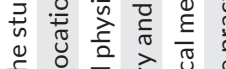

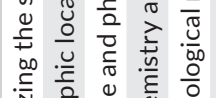
.

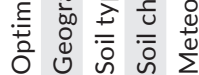
要

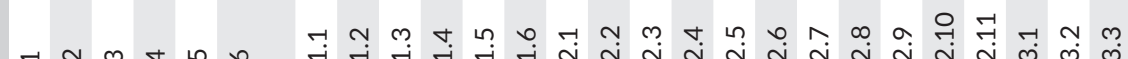

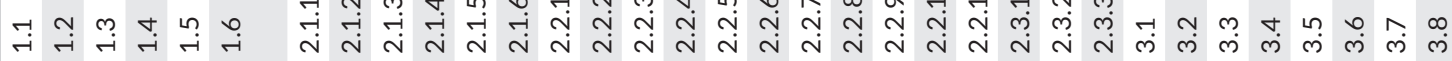

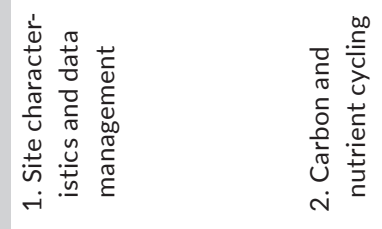
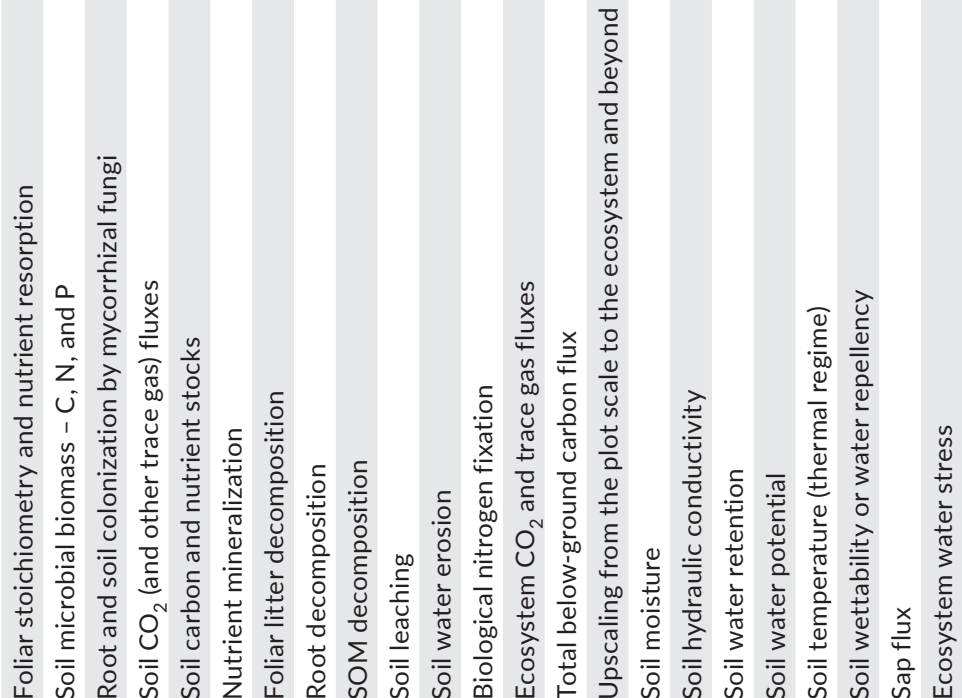

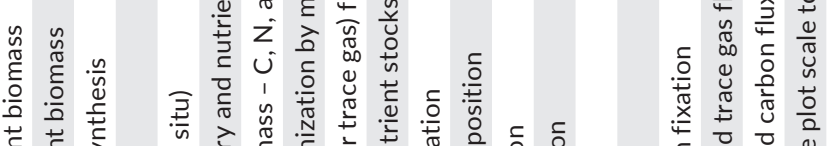

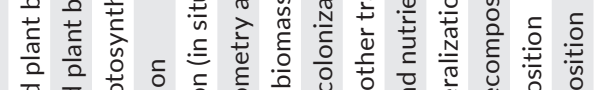




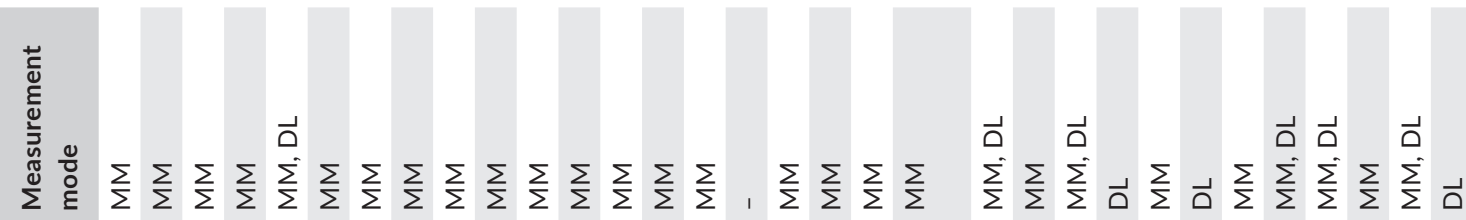

$\frac{\dot{m}}{\frac{\Delta}{3}}$

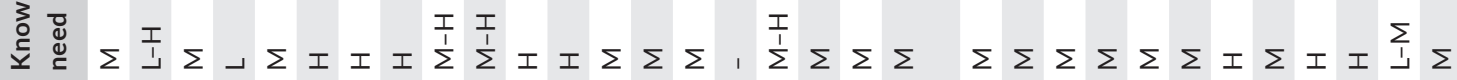

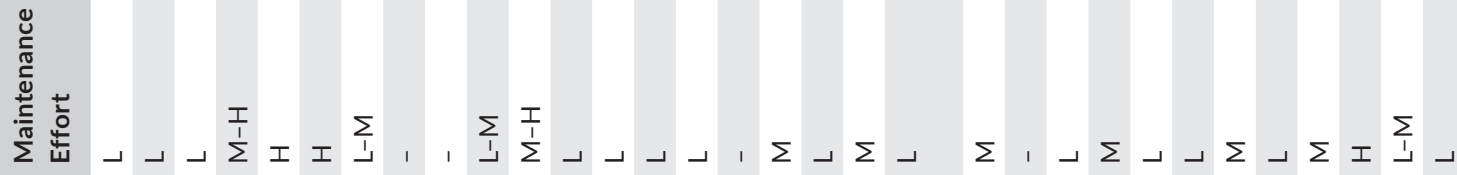

总

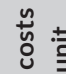

竞 $\frac{\dot{x}}{x}$

$\stackrel{\Psi}{\Psi}$

$\underset{\Psi}{\Psi} \underset{\Psi}{\Psi}$

产

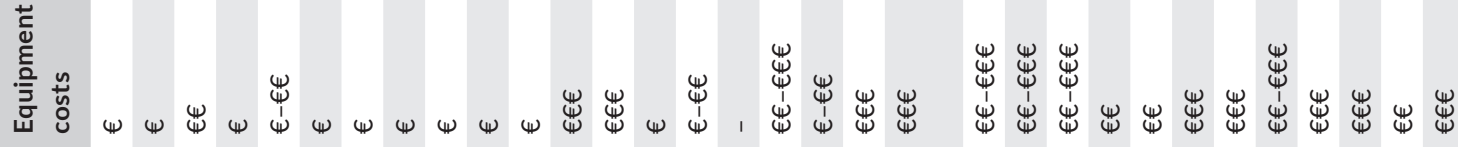

矛

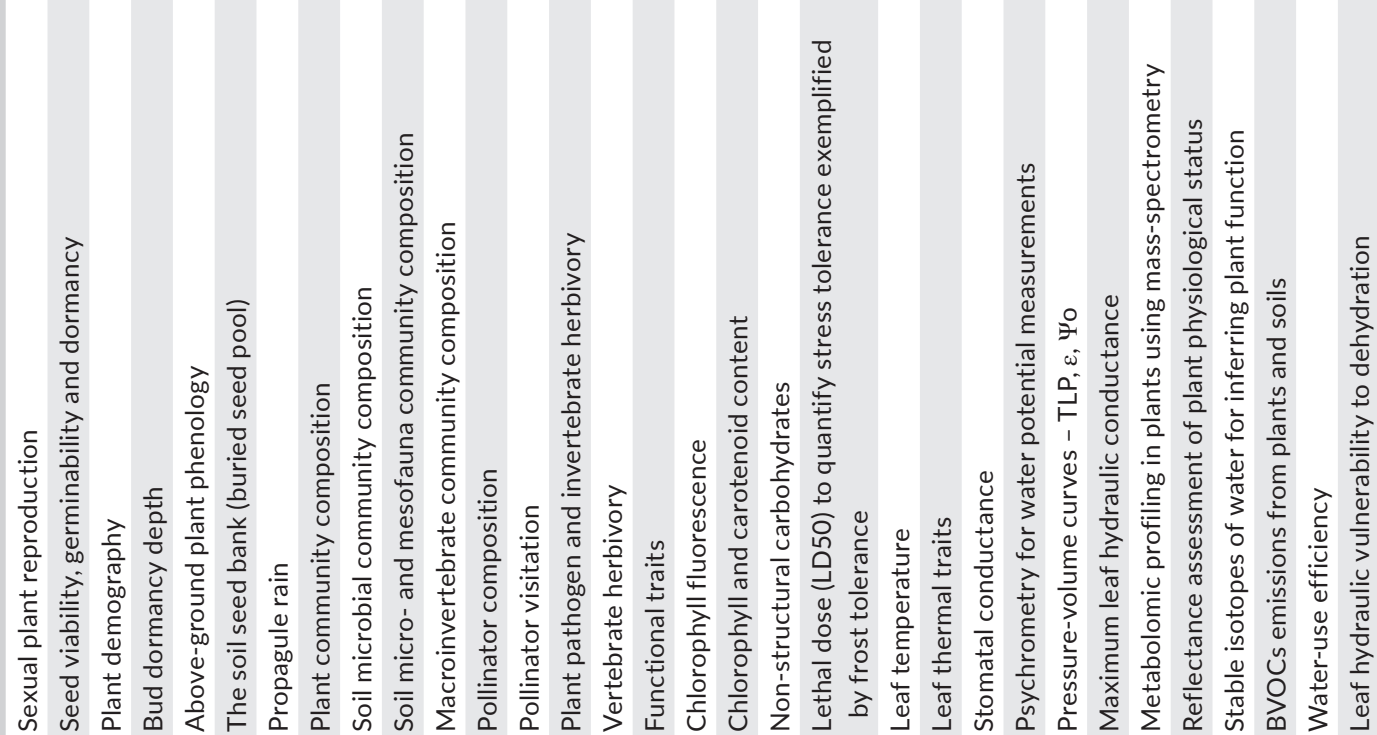

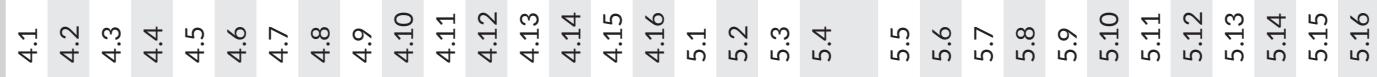

䍃

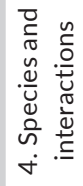

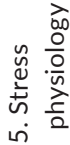




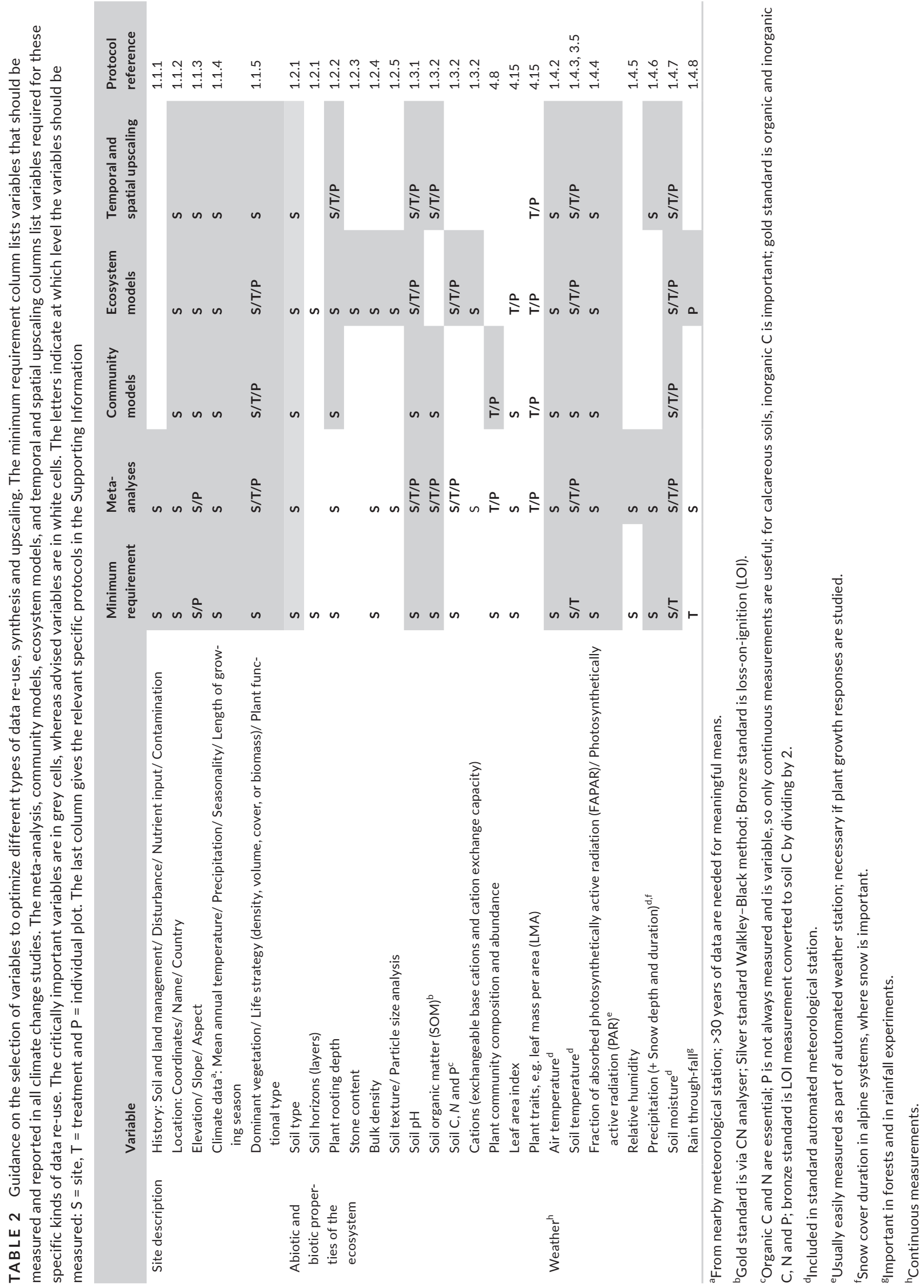


Alongside the planning of the study design and data collection, the 'data cycle' in a research project - creating, processing, documenting, sharing, storing and re-using data - should also be planned, follow standardized practice and be well structured and documented (British Ecological Society, 2018; Poisot, Bruneau, Gonzalez, Gravel, \& PeresNeto, 2019). Good data management practice is a key element of 'preproducible' research practice, a term describing a holistic approach to reproducible science (Stark, 2018). We argue that good data management practice is a key step in overcoming the challenges related to the 'data availability filter' (Figure 1) and thus in creating opportunities for data re-use, synthesis and upscaling. Funding bodies and publishers are increasingly recognizing this, and now often require data management plans and open science practice (British Ecological Society, 2018). We therefore include guidance on open science practice, reproducible workflow and data management in this chapter.

\section{2 | Chapter 2: Carbon and nutrient cycling}

The cycles of carbon and nutrients involve many ecological processes that are all sensitive to climate change (Bai et al., 2013; Yue et al., 2017), including photosynthesis, above- and below-ground plant growth, autotrophic and heterotrophic respiration, organic matter decomposition and nutrient mineralization. Even minor changes in any of these processes, or in the balance between them, can have implications for biodiversity and ecosystems, which again can impact strongly on ecosystem goods and services such as provisioning of food and fibre, water regulation and carbon sequestration (Trumbore, Brando, \& Hartmann, 2015).

In the carbon and nutrient cycling chapter (Supporting Information S2), we focus on the main components of the terrestrial carbon cycle, including above- and below-ground processes, pools and fluxes. Nutrients are also included, but limited to pools and processes that are linked to carbon cycling and ecosystem feedbacks to climate. We stratify measurements into three thematic protocols (plants, soil and ecosystems) that are particularly relevant when considering carbon and nutrient cycling processes within terrestrial ecosystems.

\section{3 | Chapter 3: Water cycling}

Ecosystems play key roles in water and energy cycles, with feedbacks to climate. The understanding of the water and energy exchange between the soil, plants and the atmosphere is still a major research challenge in climate change research because of difficulties in some of the measurements, which are needed to complete the water and energy balances. Water that enters the ecosystem via precipitation will be separated into evaporation, infiltration, transpiration by plants, drainage to groundwater and (temporary) storage in the soil. All these water fluxes need to be determined to fully understand the water and energy exchange between the ecosystem and the atmosphere.

In the water cycling chapter (Supporting Information S3), we start with soil hydraulic measurements, which include soil moisture, hydraulic conductivity, water retention and water potential. The methods included are key to determining parameters that link to, or are used in, modelling the soil-plant-atmosphere continuum. We also provide guidelines to quantify the ecosystem water stress aiming to facilitate comparison and syntheses across studies. We further include measurements used to track the progress of water through the plant and back to the atmosphere.

\subsection{Chapter 4: Species and interactions}

As discussed above, plants and the interactions in which they participate play key roles in terrestrial ecosystems. Impacts of climate change on ecosystems and their functioning are therefore to a large extent, mediated through the plant-soil food web, both through changes in the abundance and diversity of organisms, and through changes in their interactions (competition, mutualism, grazing, predation, decomposition, etc.).

In the species and interactions chapter (Supporting Information S4), we provide guidance on quantifying the consequences of climate change for key organisms, biodiversity components and ecological processes across the plant-soil food web. At the level of populations, we cover vital rates such as reproduction, recruitment, growth, mortality and phenology, as well as the overall impacts on the dynamics and growth rates of populations. At the community level, we provide guidance on the assessment of impacts on plant-, invertebrate- and microbial-species composition, abundance and diversity. For plants, we consider both aboveand below-ground diversity, as well as community-level dynamics in the form of propagule rain. With regard to species interactions, we cover pollination, vertebrate and invertebrate herbivory, plant predation and pathogens, and decomposition. We also provide a short motivation for, and link to, the plant traits protocol (PérezHarguindeguy et al., 2013). This chapter does not cover organism responses at the individual level, which are dealt with in chapter 5 on stress physiology (see below).

\section{5 | Chapter 5: Stress physiology}

In uncovering how climate change will affect plants and ecosystems, ecophysiology provides the means to mechanistically predict when tolerance limits are exceeded, and therefore when changes in the functioning of individual plants, species and entire ecosystems should occur. However, generalizations drawn from ecophysiological measurements have specific methodological challenges related to factors such as microclimate versus tissue temperature (De Boeck, Velde, Groote, \& Nijs, 2016; Michaletz et al., 2016), acclimation (Neuner \& Buchner, 2012) and scaling up from leaves to whole organisms or even ecosystems.

In the stress physiology chapter (Supporting Information S5), we describe a series of physiological or related measurements that are useful in climate change research. We focus mostly on their use as 
indicators of stress, attained through determination of compounds (e.g. chlorophyll and carotenoid content, non-structural carbohydrates), plant functional traits (e.g. reflectance, leaf hydraulic conductivity, leaf thermal properties, stable isotopes of carbon and water) and measurements that directly characterize or assess stress and tolerance.

\section{4 | DISCUSSION - ADDING VALUE THROUGH BETTER COORDINATION OF CLIMATE CHANGE ECOLOGY}

\subsection{The case for standardized data collection and reporting}

Variation in the reporting of basic site and experimental characteristics or in measurement methodologies substantially reduces the potential data (re-)use for analyses and comparisons across studies. Comprehensive comparisons across studies are therefore often hampered by (a) unrecorded factors increasing the unexplained variance in the data, (b) incompatible reporting leading to loss of information in the data (e.g. necessitate a simplification from quantitative to factor or qualitative variables) and (c) failure to report key (co)variates reducing the sample size (e.g. if studies have to be excluded from a synthesis) (Gerstner et al., 2017; Haddaway \& Verhoeven, 2015). Using standardized protocols and reporting - to the extent that these are appropriate for the individual study - will therefore substantially increase the potential downstream use of data and added value of individual studies (affecting both filters; Figure 1).

Another challenge relates to specific parameters that are important for syntheses and meta-analyses, but which are often not measured or reported in stand-alone studies (affecting the data availability filter; Figure 1). For example, nutrient availability and nutrient dynamics may not be important in all individual studies but are increasingly being recognized as key drivers of across-site variation in ecosystem properties, dynamics and responses to climate and global changes (De Graaff, Van Groeningen, Six, Hungate, \& Van Kessel, 2006; Janssens et al., 2010; Ren et al., 2017; Stevens et al., 2015; Terrer, Vicca, Hungate, Phillips, \& Prentice, 2016; Vicca, Luyssaert, et al., 2012). Carbon-cycle models have traditionally overlooked the role of nutrient availability, but the overwhelming evidence of its dominant role is now encouraging the modelling community to address the roles of nitrogen and, more recently, phosphorus (Goll et al., 2012; Peñuelas et al., 2013; Wang, Law, \& Pak, 2010). While the scientific community is increasingly acknowledging the importance of nitrogen, phosphorus and other nutrients for understanding and projecting the carbon cycle, there is still a significant lack of informative and comparable datasets at regional and global scales (Vicca et al., 2018). In the Site characteristics and data management chapter, we therefore provide a section on what variables to measure to enable disentangling the role of nutrients in carbon synthesis studies (summarized in Table 2).

\section{2 | The case for using standardized and relevant units and scales}

Several of the key variables and covariates for inter-study comparisons (Table 2) include data and parameters that may be measured in different units or scales, depending on the research tradition in the specific fields. Such variables are, or can easily be made, comparable across studies, as long as the necessary information needed for conversions are also reported along with the original variables (these may relate to area/volume, climatic data, vegetation characterization, soil properties, nutrients; Table 2; affecting the compatibility filter, Figure 1). For example, changes in soil organic carbon in response to a manipulation are typically reported either per unit area or as a weight percentage. These metrics are both valid, but they are not comparable unless the data necessary for conversion (bulk density and sampling depth) are provided. The necessary information for recalculation or conversion across reporting traditions should therefore be recorded and reported.

A second challenge relates to the need to quantify the treatments as experienced by the biota. For example, precipitation manipulation experiments typically report the amount of water added or removed, but the manipulation as experienced by the biota may deviate substantially from what is reflected in the absolute or percentage change in precipitation. Specifically, soil water availability is influenced by many factors, including soil water-holding capacity, run-off, hydrological legacy, rooting depth and drainage (Vicca, Luyssaert, et al., 2012). Hence, assessing water availability in a standardized way will substantially improve our understanding of the sensitivity of ecosystems to the manipulations and facilitate cross-experimental comparisons (see protocol 3.8 on Ecosystem water stress).

\subsection{The case for upscaling through models}

Various types of mechanistic models can be used to generalize and extrapolate the data collected from in situ climate change studies in space and time. The potential of model-data interaction and its potential high impact, however, is often forgotten during experimental planning. Here, we want to illustrate the importance of early project planning for future data use (Table 2). For example, soil $\mathrm{pH}$ as an easy and low-cost measure may have been traditionally measured at the site level (lowest resolution), but in order to be a useful variable in meta-analyses, ecosystem models and temporal and spatial upscaling, soil $\mathrm{pH}$ data are more valuable if measured at a higher resolution (e.g. treatment or plot level). Thus, investing time in considering the aspired impact of the data-to-becollected already in the project planning phase can direct budget investments and will be beneficial for the wider experimental and modelling community.

Purely statistical models attempt to describe cause-and-effect based on independent measurements of key processes. On the other hand, process-based models are built on a theoretical 
understanding of relevant ecological processes and provide understanding about specific responses to various environmental conditions. Here, we suggest three strategies for stimulating information flow between models and experiments and/or observational studies. First, data-model comparisons can be used as a tool to directly test hypotheses, where observations are compared directly against model output. Second, experimental and/ or observational data can be used as for model calibration tool, where parameters and predictor variables measured at a site or within a treatment are used to calibrate the model. In this case, the uncalibrated response variables can be compared to the model output; flexible parameterization can be considered a hypothesis (i.e. a form of sensitivity analysis) and can be used to inform the final model selection. Finally, the model parameters can be used in process-based models to 'tune' or 'benchmark' the model, which means that the model is simply fitted to the model-derived data. In this latter case, the model provides no hypothesis test, but simply synthesizes the data within the logical structure provided by the model (Luo et al., 2012). Each of these strategies has its place, but the difference in objectives and data requirements needs to be recognized.

To give an example, sensitivity analyses often identify similar variables as important for similar models. The BIOME-BGC model, which describes biogeochemical processes, is especially sensitive to leaf area index, cumulative soil water-holding capacity, leaf mass to area ratio, temperature and some measure of nutrient status (White, Thornton, Running, \& Nemani, 2000). Similarly, Yang et al. (2016) described a sensitivity test of a model predicting the distribution of plant functional types. They found that leaf area index, leaf nitrogen per mass and leaf mass per area provided a particularly powerful combination of predictions. When exercised with changes in temperature and precipitation, the model predicted, for example, that boreal forest, boreal steppe and tundra would lose significant area. By measuring and reporting the variables needed to meet the data requirements of different types of models (Table 2), the information flow between empirical studies and modelling will be increased.

\subsection{The case for considering new mechanisms and drivers under future climates}

As the climate warms and rainfall patterns intensify in many regions across the globe, mechanisms and driving factors that are currently of minor importance could become more dominant in the future. Thus, new variables might need to be considered for measurement protocols to adequately track modifications in ecosystems under a changed climate. In particular, drought events are expected to occur more often, to last longer or to be more severe in many regions (Prudhomme et al., 2014; Touma, Ashfaq, Nayak, Kao, \& Diffenbaugh, 2015). Conversely, increased rainfall intensities and flash flooding during the growing season are also predicted (Kendon et al., 2014), leading to a short-term rise in the availability of water. Drier conditions could have consequences for the drivers and mechanisms operating in biogeochemical cycles. For example, rain might periodically be absent, thus driving the ecosystem to pass a threshold and start relying on non-rainfall water inputs (occult precipitation, such as dew and fog) for plant, litter and soil processes (Gliksman et al., 2017; Hill, Dawson, Shelef, \& Rachmilevitch, 2015; McHugh, Morrissey, Reed, Hungate, \& Schwartz, 2015). Moreover, abiotic processes, such as photochemical and thermal processes, start to kick in after passing heat and drought thresholds (Austin \& Vivanco, 2006; McCalley \& Sparks, 2009). Methodologies need to be adapted to capture such changes in drivers and mechanisms. For example, litterbags to study decomposition should transmit UV radiation and should only minimally affect the energy balance of litter to prevent interfering with dew formation. In addition to the need of measurement devices to consider these mechanisms and allow their quantification, the relevant drivers have to be measured with affordable equipment, such as UV irradiance by UV sensors and duration of dew by leaf wetness sensors. In general, this illustrates how novel future climates and conditions will necessitate the consideration of new drivers and mechanisms.

\section{5 | CONCLUSIONS}

Climate change experiments and observational studies are increasingly being conducted across a broad range of habitats and regions. Experiments are generally designed to disentangle complex and interactive drivers, causal relationships, response surfaces and underlying mechanisms, whereas observational studies document large-scale temporal and spatial patterns. The growing interest in data re-use, synthesis and upscaling within and across experiments and observations highlights challenges and pitfalls regarding the downstream use of knowledge from these studies, especially regarding data availability and data compatibility across studies (Denny et al., 2014; Firbank et al., 2017; Vicca, Gilgen, et al., 2012) and the lack of basic study information or covariates necessary for comparison (Gerstner et al., 2017; Haddaway \& Verhoeven, 2015; Halbritter et al., 2018).

To overcome these challenges, we provide a handbook with guidance on the selection of response variables, protocols for standardized measurements of these variables and advice on data reporting and management. The ClimEx handbook summarizes best-practice methodologies emerging from major ecological research networks and studies, as synthesized by 115 experts from across relevant research fields. Our ambition is that this community effort will facilitate awareness by the next generation (and the older generation) climate- and global-change scientists of standardized methods to promote data availability, compatibility and transparency. We envision improved research practices that will not only result in better returns on the time and money invested in individual research projects, but will especially facilitate second-order research outputs across projects and scientific disciplines. More general, this should lead to a better connection of 
scientific communities and disciplines. The ultimate goal is to optimize the quality and impact of our science to fulfil society's needs in a changing world.

\section{ACKNOWLEDGEMENTS}

We thank the ClimMani core group for the opportunity to realize this handbook, Linn Vassvik, Christine Pötsch, William Erazo Garcia and Siri V. Haugum for assisting in the collection of existing protocols, and Cathy Jenks for reading all the protocols thrice, checking the language, flow, logic and all references. The authors were funded by different national and international research agencies while contributing to this work, but in the interest of the word count we are not mentioning these individually. This study was funded by the ClimMani COST Action ES1308 (2014-2018).

\section{AUTHORS' CONTRIBUTIONS}

H.J.D.B. and V.V. conceived the idea and initiated the project. A.H.H. and V.V. led the project, which included developing the original idea, elaborating on the structure, content and workflow of the paper, organizing meetings to discuss ideas, methodology, data collection, organizing the writing and reviewing of the protocols, and leading the writing of the manuscript. H.J.D.B., A.E.E., A.J., S.R., D.A.R., S.V. and P.W. led the collection and writing of the five protocol chapters and were involved in conceiving the ideas, designing methodology and contributing critically to the drafts of the manuscript. B.B., C.T.C., M.E., J.M.G., R.G., K.H., I.K.S., H.L., S.L., J.M. and J.P. contributed to developing ideas, selecting and describing methodologies, and writing drafts of the protocols and manuscript. The ClimMani working group contributed to writing and reviewing individual protocols (see each individual protocol for author and reviewer contributions). All authors gave final approval for publication.

\section{DATA AVAILABILITY STATEMENT}

This manuscript does not use data.

\section{ORCID}

Aud H. Halbritter (iD) https://orcid.org/0000-0003-2597-6328 Hans J. De Boeck iD https://orcid.org/0000-0003-2180-8837 Amy E. Eycott (iD https://orcid.org/0000-0002-8609-1091 Sabine Reinsch iD https://orcid.org/0000-0003-4649-0677 David A. Robinson iD https://orcid.org/0000-0001-7290-4867 Sara Vicca iD https://orcid.org/0000-0001-9812-5837 Bernd Berauer (iD https://orcid.org/0000-0002-9472-1532 Casper T. Christiansen (iD https://orcid.org/0000-0002-4526-614X Marc Estiarte iD https://orcid.org/0000-0003-1176-8480 Anke Jentsch (iD https://orcid.org/0000-0002-2345-8300 Hanna Lee iD https://orcid.org/0000-0002-2003-4377 Sune Linder (iD https://orcid.org/0000-0001-9036-5422 Josep Peñuelas (iD https://orcid.org/0000-0002-7215-0150 Inger Kappel Schmidt (iD https://orcid.org/0000-0003-3880-2060 Ellen Stuart-Haëntjens (iD https://orcid.org/0000-0001-9901-7643 Peter Wilfahrt iD https://orcid.org/0000-0003-1594-6512 Vigdis Vandvik (iD) https://orcid.org/0000-0003-4651-4798

\section{REFERENCES}

Arft, A. M., Walker, M. D., Gurevitch, J., Alatalo, J. M., Bret-Harte, M. S., Dale, M., ... Wookey, P. A. (1999). Responses of tundra plants to experimental warming: Meta-analysis of the international tundra experiment. Ecological Monographs, 69(4), 491-511. https://doi. org/10.2307/2657227

Austin, A. T., \& Vivanco, L. (2006). Plant litter decomposition in a semiarid ecosystem controlled by photodegradation. Nature, 442(7102), 555-558. https://doi.org/10.1038/nature05038

Bai, E., Li, S., Xu, W., Li, W., Dai, W., \& Jiang, P. (2013). A meta-analysis of experimental warming effects on terrestrial nitrogen pools and dynamics. New Phytologist, 199(2), 441-451. https://doi.org/10.1111/ nph.12252

Bar-On, Y. M., Phillips, R., \& Milo, R. (2018). The biomass distribution on Earth. Proceedings of the National Academy of Sciences USA, 115(25), 6506-6511. https://doi.org/10.1073/pnas.1711842115

Beier, C., Beierkuhnlein, C., Wohlgemuth, T., Penuelas, J., Emmett, B., Körner, C., ... Hansen, K. (2012). Precipitation manipulation experiments-challenges and recommendations for the future. Ecology Letters, 15(8), 899-911. https://doi. org/10.1111/j.1461-0248.2012.01793.x

Bertora, C., Blankman, D., Delle Vedove, G., Firbank, L., Frenzel, M., Grignani, C., ... Stadler, J. (2013). Handbook of standardised ecosystem protocols - Infrastructures for experimentation in ecosystem research. ExpeER. Retrieved from http://expeeronline.eu/images/ExpeERDocuments/Handbook_of_standardized_ecosystem_protocols.pdf

Borer, E. T., Harpole, W. S., Adler, P. B., Lind, E. M., Orrock, J. L., Seabloom, E. W., \& Smith, M. D. (2014). Finding generality in ecology: A model for globally distributed experiments. Methods in Ecology and Evolution, 5(1), 65-73. https://doi.org/10.1111/2041-210X.12125

British Ecological Society. (2017). A guide to reproducible code in ecology and evolution (K. Harrison, Ed.). British Ecological Society. Retrieved from www.britishecologicalsociety.org/publications/guides-to/

British Ecological Society. (2018). A guide to data management in ecology and evolution (K. Harrison, Ed.). British Ecological Society. Retrieved from https://www.britishecologicalsociety.org/wp-content/uploa ds/2019/06/BES-Guide-Data-Management- 2019.pdf

Clemmensen, K. E., Bahr, A., Ovaskainen, O., Dahlberg, A., Ekblad, A., Wallander, H., ... Lindahl, B. D. (2013). Roots and associated fungi drive long-term carbon sequestration in boreal forest. Science, 339(6127), 1615-1618. https://doi.org/10.1126/science.1231923

Cornelissen, J. H. C., Lavorel, S., Garnier, E., Díaz, S., Buchmann, N., Gurvich, D. E., ... Poorter, H. (2003). A handbook of protocols for standardised and easy measurement of plant functional traits worldwide. Australian Journal of Botany, 51(4), 335-380. https://doi. org/10.1071/BT02124

De Boeck, H. J., Velde, H. V. D., Groote, T. D., \& Nijs, I. (2016). Ideas and perspectives: Heat stress: More than hot air. Biogeosciences, 13(20), 5821-5825. https://doi.org/10.5194/bg-13-5821-2016

De Boeck, H. J., Vicca, S., Roy, J., Nijs, I., Milcu, A., Kreyling, J., ... Beier, C. (2015). Global change experiments: Challenges and opportunities. BioScience, 65(9), 922-931. https://doi.org/10.1093/biosci/biv099

De Graaff, M.-A., Van Groeningen, K.-J., Six, J., Hungate, B., \& Van Kessel, C. (2006). Interactions between plant growth and soil nutrient cycling under elevated $\mathrm{CO}_{2}$ : A meta-analysis. Global Change Biology, 12(11), 2077-2091. https://doi.org/10.1111/j.1365-2486.2006.01240.x

Defila, C., \& Clot, B. (2001). Phytophenological trends in Switzerland. International Journal of Biometeorology, 45(4), 203-207. https://doi. org/10.1007/s004840100101

Denny, E. G., Gerst, K. L., Miller-Rushing, A. J., Tierney, G. L., Crimmins, T. M., Enquist, C. A. F., ... Weltzin, J. F. (2014). Standardized phenology monitoring methods to track plant and animal activity for science and resource management applications. International Journal of Biometeorology, 58(4), 591-601. https://doi.org/10.1007/ s00484-014-0789-5 
Elmendorf, S. C., Henry, G. H. R., Hollister, R. D., Björk, R. G., Bjorkman, A. D., Callaghan, T. V., ... Wookey, P. A. (2012). Global assessment of experimental climate warming on tundra vegetation: Heterogeneity over space and time. Ecology Letters, 15(2), 164-175. https://doi. org/10.1111/j.1461-0248.2011.01716.x

Emmett, B. A., Beier, C., Estiarte, M., Tietema, A., Kristensen, H. L., Williams, D., ... Sowerby, A. (2004). The response of soil processes to climate change: Results from manipulation studies across an environmental gradient. Ecosystems, 7, 625-637. https://doi.org/10.1007/ s10021-004-0220-x

Emmett, B. A., Reynolds, B., Chamberlain, P. M., Rowe, E., Spurgeon, D., Brittain, S. A., ...Woods, C. (2010). Countryside survey: soils report from 2007 (No. 9/07). Centre for Ecology \& Hydrology (Natural Environment Research Council).

Estiarte, M., Vicca, S., Peñuelas, J., Bahn, M., Beier, C., Emmett, B. A., ... Janssens, I. A. (2016). Few multiyear precipitation-reduction experiments find a shift in the productivity-precipitation relationship. Global Change Biology, 22(7), 2570-2581. https://doi.org/10.1111/ gcb.13269

Fanin, N., Kardol, P., Farrell, M., Kempel, A., Ciobanu, M., Nilsson, M.-C., ... Wardle, D. A. (2019). Effects of plant functional group removal on structure and function of soil communities across contrasting ecosystems. Ecology Letters, 22(7), 1095-1103. https://doi.org/10.1111/ele.13266

Firbank, L. G., Bertora, C., Blankman, D., Delle Vedove, G., Frenzel, M., Grignani, C., ... Kunin, W. E. (2017). Towards the co-ordination of terrestrial ecosystem protocols across European research infrastructures. Ecology and Evolution, 7(11), 3967-3975. https://doi. org/10.1002/ece3.2997

Fitter, A. H., \& Fitter, R. S. R. (2002). Rapid changes in flowering time in British plants. Science, 296(5573), 1689-1691. https://doi. org/10.1126/science.1071617

Fraser, L. H., Henry, H. A. L., Carlyle, C. N., White, S. R., Beierkuhnlein, C., Cahill, J. F., ... Turkington, R. (2013). Coordinated distributed experiments: An emerging tool for testing global hypotheses in ecology and environmental science. Frontiers in Ecology and the Environment, 11(3), 147-155. https://doi.org/10.1890/110279

Gerstner, K., Moreno-Mateos, D., Gurevitch, J., Beckmann, M., Kambach, S., Jones, H. P., \& Seppelt, R. (2017). Will your paper be used in a meta-analysis? Make the reach of your research broader and longer lasting. Methods in Ecology and Evolution, 8(6), 777-784. https://doi. org/10.1111/2041-210X.12758

Gliksman, D., Rey, A., Seligmann, R., Dumbur, R., Sperling, O. R., Navon, Y., ... Grünzweig, J. M. (2017). Biotic degradation at night, abiotic degradation at day: Positive feedbacks on litter decomposition in drylands. Global Change Biology, 23(4), 1564-1574. https://doi. org/10.1111/gcb.13465

Goll, D. S., Brovkin, V., Parida, B. R., Reick, C. H., Kattge, J., Reich, P. B., ... Niinemets, Ü. (2012). Nutrient limitation reduces land carbon uptake in simulations with a model of combined carbon, nitrogen and phosphorus cycling. Biogeosciences, 9, 3547-3569. https://doi. org/10.5194/bg-9-3547-2012

Guittar, J., Goldberg, D., Klanderud, K., Telford, R. J., \& Vandvik, V. (2016). Can trait patterns along gradients predict plant community responses to climate change? Ecology, 97(10), 2791-2801. https:// doi.org/10.1002/ecy.1500

Haddaway, N. R., \& Verhoeven, J. T. A. (2015). Poor methodological detail precludes experimental repeatability and hampers synthesis in ecology. Ecology and Evolution, 5(19), 4451-4454. https://doi. org/10.1002/ece3.1722

Halbritter, A. H., Alexander, J. M., Edwards, P. J., \& Billeter, R. (2013). How comparable are species distributions along elevational and latitudinal temperature gradients? Global Ecology and Biogeography, 22(11), 1228-1237. https://doi.org/10.1111/geb.12066

Halbritter, A. H., Fior, S., Keller, I., Billeter, R., Edwards, P. J., Holderegger, R., ... Alexander, J. M. (2018). Trait differentiation and adaptation of plants along elevation gradients. Journal of Evolutionary Biology, 31(6), 784-800. https://doi.org/10.1111/jeb.13262

Hill, A. J., Dawson, T. E., Shelef, O., \& Rachmilevitch, S. (2015). The role of dew in Negev Desert plants. Oecologia, 178(2), 317-327. https://doi. org/10.1007/s00442-015-3287-5

Hillebrand, H., \& Gurevitch, J. (2013). Reporting standards in experimental studies. Ecology Letters, 16(12), 1419-1420. https://doi. org/10.1111/ele.12190

IPBES. (2019). Summary for policymakers of the global assessment report on biodiversity and ecosystem services of the Intergovernmental Science-Policy Platform on Biodiversity and Ecosystem Services.

Janssens, I. A., Dieleman, W., Luyssaert, S., Subke, J.-A., Reichstein, M., Ceulemans, R., ... Law, B. E. (2010). Reduction of forest soil respiration in response to nitrogen deposition. Nature Geoscience, 3, 315322. https://doi.org/10.1038/ngeo844

Kendon, E. J., Roberts, N. M., Fowler, H. J., Roberts, M. J., Chan, S. C., \& Senior, C. A. (2014). Heavier summer downpours with climate change revealed by weather forecast resolution model. Nature Climate Change, 4, 570-576. https://doi.org/10.1038/nclimate2258

Keuskamp, J. A., Dingemans, B. J. J., Lehtinen, T., Sarneel, J. M., \& Hefting, M. M. (2013). Tea Bag Index: A novel approach to collect uniform decomposition data across ecosystems. Methods in Ecology and Evolution, 4(11), 1070-1075. https://doi.org/10.1111/2041-210X.12097

Knapp, A. K., Avolio, M. L., Beier, C., Carroll, C. J. W., Collins, S. L., Dukes, J. S., ... Smith, M. D. (2017). Pushing precipitation to the extremes in distributed experiments: Recommendations for simulating wet and dry years. Global Change Biology, 23(5), 1774-1782. https://doi. org/10.1111/gcb.13504

Lu, M., Zhou, X., Yang, Q., Li, H., Luo, Y., Fang, C., ... Li, B. O. (2013). Responses of ecosystem carbon cycle to experimental warming: A meta-analysis. Ecology, 94(3), 726-738. https://doi. org/10.1890/12-0279.1

Luo, Y., Melillo, J., Niu, S., Beier, C., Clark, J. S., Classen, A. T., ... Torn, M. S. (2011). Coordinated approaches to quantify long-term ecosystem dynamics in response to global change. Global Change Biology, 17, 843-854. https://doi.org/10.1111/j.1365-2486.2010.02265.x

Luo, Y. Q., Randerson, J. T., Abramowitz, G., Bacour, C., Blyth, E., Carvalhais, N., ... Zhou, X. H. (2012). A framework for benchmarking land models. Biogeosciences, 9(10), 3857-3874. https://doi. org/10.5194/bg-9-3857-2012

McCalley, C. K., \& Sparks, J. P. (2009). Abiotic gas formation drives nitrogen loss from a desert ecosystem. Science, 326(5954), 837-840. https://doi.org/10.1126/science.1178984

McHugh, T. A., Morrissey, E. M., Reed, S. C., Hungate, B. A., \& Schwartz, E. (2015). Water from air: An overlooked source of moisture in arid and semiarid regions. Scientific Reports, 5, 13767. https://doi. org/10.1038/srep13767

Medlyn, B. E., Zaehle, S., De Kauwe, M. G., Walker, A. P., Dietze, M. C., Hanson, P. J., ... Norby, R. J. (2015). Using ecosystem experiments to improve vegetation models. Nature Climate Change, 5, 528-534. https://doi.org/10.1038/nclimate2621

Michaletz, S. T., Weiser, M. D., McDowell, N. G., Zhou, J., Kaspari, M., Helliker, B. R., \& Enquist, B. J. (2016). The energetic and carbon economic origins of leaf thermoregulation. Nature Plants, 2, 16147. https:// doi.org/10.1038/nplants.2016.129

Milner, C., \& Elfyn Hughes, R. (1968). Methods for the measurement of the primary production of grassland (vol. 6). Oxford: IBP Handbook.

Neuner, G., \& Buchner, O. (2012). Dynamics of tissue heat tolerance and thermotolerance of PS II in alpine plants. In C. Lütz (Ed.), Plants in alpine regions: Cell physiology of adaption and survival strategies (pp. 61-74). Vienna: Springer.

Nosek, B. A., Alter, G., Banks, G. C., Borsboom, D., Bowman, S. D., Breckler, S. J., ... Yarkoni, T. (2015). Promoting an open research culture. Science, 348(6242), 1422-1425. https://doi.org/10.1126/scien ce.aab2374 
Olsen, S. L., Töpper, J. P., Skarpaas, O., Vandvik, V., \& Klanderud, K. (2016). From facilitation to competition: Temperature-driven shift in dominant plant interactions affects population dynamics in semi-natural grasslands. Global Change Biology, 22(5), 1915-1926. https://doi. org/10.1111/gcb.13241

Pacifici, M., Foden, W. B., Visconti, P., Watson, J. E. M., Butchart, S. H. M., Kovacs, K. M., ... Rondinini, C. (2015). Assessing species vulnerability to climate change. Nature Climate Change, 5, 215-224. https://doi. org/10.1038/nclimate2448

Peñuelas, J., Poulter, B., Sardans, J., Ciais, P., van der Velde, M., Bopp, L., ... Janssens, I. A. (2013). Human-induced nitrogen-phosphorus imbalances alter natural and managed ecosystems across the globe. Nature Communications, 4, 2934. https://doi.org/10.1038/ncomm s3934

Pérez-Harguindeguy, N., Díaz, S., Garnier, E., Lavorel, S., Poorter, H., Jaureguiberry, P., ... Cornelissen, J. H. C. (2013). New handbook for standardised measurement of plant functional traits worldwide. Australian Journal of Botany, 61, 167-234. https://doi.org/10.1071/ BT12225

Poisot, T., Bruneau, A., Gonzalez, A., Gravel, D., \& Peres-Neto, P. (2019). Ecological data should not be so hard to find and reuse. Trends in Ecology \& Evolution, 34(6), 494-496. https://doi.org/10.1016/j. tree.2019.04.005

Prudhomme, C., Giuntoli, I., Robinson, E. L., Clark, D. B., Arnell, N. W., Dankers, R., ... Wisser, D. (2014). Hydrological droughts in the 21st century, hotspots and uncertainties from a global multimodel ensemble experiment. Proceedings of the National Academy of Sciences USA, 111(9), 3262-3267. https://doi.org/10.1073/pnas.12224 73110

Ren, H., Xu, Z., Isbell, F., Huang, J., Han, X., Wan, S., ... Fang, Y. (2017). Exacerbated nitrogen limitation ends transient stimulation of grassland productivity by increased precipitation. Ecological Monographs, 87(3), 457-469. https://doi.org/10.1002/ecm.1262

Sack, L., Cornwell, W. K., Santiago, L. S., Barbour, M. M., Choat, B., Evans, J. R., ... Nicotra, A. (2010). A unique web resource for physiology, ecology and the environmental sciences: PrometheusWiki. Functional Plant Biology, 37, 687-693. https://doi.org/10.1071/FP10097

Schmidt, I. K., Larsen, K. S., Ransijn, J., Arndal, M. F., Tietema, A., De Angelis, P., ...Guidolotti, G. (2014). INCREASE - An integrated network on climate change activities on shrubland ecosystems: final report. Department of Geosciences and Natural Resource Management, University of Copenhagen. Retrieved from www.increase.ku.dk

Schuur, E. A. G., McGuire, A. D., Schädel, C., Grosse, G., Harden, J. W., Hayes, D. J., ... Vonk, J. E. (2015). Climate change and the permafrost carbon feedback. Nature, 520(7546), 171-179. https://doi. org/10.1038/nature14338

Sier, A., \& Monteith, D. (2016). The UK Environmental Change Network after twenty years of integrated ecosystem assessment: Key findings and future perspectives. Ecological Indicators, 68, 1-12. https://doi. org/10.1016/j.ecolind.2016.02.008

Stark, P. B. (2018). Before reproducibility must come preproducibility. Nature, 557(7707), 613. https://doi.org/10.1038/ d41586-018-05256-0

Steinbauer, M. J., Grytnes, J.-A., Jurasinski, G., Kulonen, A., Lenoir, J., Pauli, H., ... Wipf, S. (2018). Accelerated increase in plant species richness on mountain summits is linked to warming. Nature, 556(7700), 231-234. https://doi.org/10.1038/s41586-018-0005-6

Stevens, C. J., Lind, E. M., Hautier, Y., Harpole, W. S., Borer, E. T., Hobbie, S., ... Wragg, P. D. (2015). Anthropogenic nitrogen deposition predicts local grassland primary production worldwide. Ecology, 96(6), 1459-1465. https://doi.org/10.1890/14-1902.1

Terrer, C., Vicca, S., Hungate, B. A., Phillips, R. P., \& Prentice, I. C. (2016). Mycorrhizal association as a primary control of the $\mathrm{CO}_{2}$ fertilization effect. Science, 353(6294), 72-74. https://doi.org/10.1126/scien ce.aaf4610
Touma, D., Ashfaq, M., Nayak, M. A., Kao, S.-C., \& Diffenbaugh, N. S. (2015). A multi-model and multi-index evaluation of drought characteristics in the 21st century. Journal of Hydrology, 526, 196-207. https ://doi.org/10.1016/j.jhydrol.2014.12.011

Trumbore, S., Brando, P., \& Hartmann, H. (2015). Forest health and global change. Science, 349(6250), 814-818. https://doi.org/10.1126/scien ce.aac6759

Verheyen, K., De Frenne, P., Baeten, L., Waller, D. M., Hédl, R., Perring, M. P., ... Bernhardt-Römermann, M. (2016). Combining biodiversity resurveys across regions to advance global change research. BioScience, 67(1), 73-83. https://doi.org/10.1093/biosci/biw150

Vicca, S., Bahn, M., Estiarte, M., Van Loon, E. E., Vargas, R., Alberti, G., ... Borken, W. (2014). Can current moisture responses predict soil $\mathrm{CO}_{2}$ efflux under altered precipitation regimes? A Synthesis of manipulation experiments. Biogeosciences, 11(11), 2991-3013. https://doi. org/10.5194/bg-11-2991-2014

Vicca,S., Gilgen, A. K., CaminoSerrano, M.,Dreesen, F.E., Dukes, J.S., Estiarte, M., ... Granier, A. (2012). Urgent need for a common metric to make precipitation manipulation experiments comparable. New Phytologist, 195(3), 518-522. https://doi.org/10.1111/j.1469-8137.2012.04224.x

Vicca, S., Luyssaert, S., Peñuelas, J., Campioli, M., Chapin, F. S. Ciais, P., ... Janssens, I. A. (2012). Fertile forests produce biomass more efficiently. Ecology Letters, 15(6), 520-526. https://doi. org/10.1111/j.1461-0248.2012.01775.x

Vicca, S., Stocker, B. D., Reed, S., Wieder, W. R., Bahn, M., Fay, P. A., ... Ciais, P. (2018). Using research networks to create the comprehensive datasets needed to assess nutrient availability as a key determinant of terrestrial carbon cycling. Environmental Research Letters, 13(12), 125006. https://doi.org/10.1088/1748-9326/aaeae7

Wang, Y. P., Law, R. M., \& Pak, B. (2010). A global model of carbon, nitrogen and phosphorus cycles for the terrestrial biosphere. Biogeosciences, 7(7), 2261. https://doi.org/10.5194/bg-7-2261-2010

White, M. A., Thornton, P. E., Running, S. W., \& Nemani, R. R. (2000). Parameterization and sensitivity analysis of the BIOME-BGC terrestrial ecosystem model: Net primary production controls. Earth Interactions, 4(3), 1-85. https://doi.org/10.1175/10873562(2000)004<0003:PASAOT>2.0.CO;2

Wu, Z., Dijkstra, P., Koch, G. W., Penuelas, J., \& Hungate, B. A. (2011). Responses of terrestrial ecosystems to temperature and precipitation change: A meta-analysis of experimental manipulation. Global Change Biology, 17(2), 927-942. https://doi. org/10.1111/j.1365-2486.2010.02302.x

Yang, Y., Zhu, Q., Peng, C., Wang, H., Xue, W., Lin, G., ... Li, S. (2016). A novel approach for modelling vegetation distributions and analysing vegetation sensitivity through trait-climate relationships in China. Scientific Reports, 6, 24110. https://doi.org/10.1038/srep24110

Yue, K., Fornara, D. A., Yang, W., Peng, Y., Peng, C., Liu, Z., \& Wu, F. (2017). Influence of multiple global change drivers on terrestrial carbon storage: Additive effects are common. Ecology Letters, 20(5), 663-672. https://doi.org/10.1111/ele.12767

\section{SUPPORTING INFORMATION}

Additional supporting information may be found online in the Supporting Information section.

How to cite this article: Halbritter AH, De Boeck HJ, Eycott $\mathrm{AE}$, et al. The handbook for standardized field and laboratory measurements in terrestrial climate change experiments and observational studies (ClimEx). Methods Ecol Evol. 2020;11: 22-37. https://doi.org/10.1111/2041-210X.13331 


\section{APPENDIX}

ClimMani Working Group: Nelson Abrantes ${ }^{1}$, María Almagro ${ }^{2}$, Inge H. J. Althuizen ${ }^{3}$, Isabel C. Barrio ${ }^{4}$, Mariska te Beest ${ }^{5,6}$, Claus Beier ${ }^{7}$, Ilka Beil ${ }^{8}$, Z. Carter Berry ${ }^{9}$, Tone Birkemoe ${ }^{10}$, Jarle W. Bjerke ${ }^{11}$, Benjamin Blonder ${ }^{12,13}$, Gesche Blume-Werry ${ }^{8}$, Gil Bohrer ${ }^{14}$, Isabel Campos $^{1}$, Lucas A. Cernusak ${ }^{15}$, Bogdan H. Chojnicki ${ }^{16}$, Bernhard J. Cosby $^{17}$, Lee T. Dickman ${ }^{18}$, Ika Djukic ${ }^{19}$, Iolanda Filella ${ }^{20,21}$, Lucia Fuchslueger $^{22}$, Albert Gargallo-Garriga ${ }^{21}$, Mark A. K. Gillespie ${ }^{23}$, Gregory R. Goldsmith9, Christopher Gough ${ }^{24}$, Fletcher W. Halliday $^{25}$, Stein Joar Hegland ${ }^{23}$, Günter $\mathrm{Hoch}^{26}$, Petr Holub ${ }^{27}$, Francesca Jaroszynska ${ }^{3}$, Daniel M. Johnson ${ }^{28}$, Scott B. Jones ${ }^{29}$ Paul Kardol ${ }^{30}$, Jan J. Keizer ${ }^{1}$, Karel Klem ${ }^{31}$, Heidi S. Konestabo ${ }^{32}$, Jürgen Kreyling ${ }^{8}$, György Kröel-Dulay ${ }^{33}$, Simon M. Landhäusser ${ }^{34}$, Klaus S. Larsen ${ }^{7}$, Niki Leblans ${ }^{22,35}$, Inma Lebron ${ }^{17}$, Marco M. Lehmann $^{36}$, Jonas J. Lembrechts ${ }^{22}$, Armando Lenz ${ }^{37}$, Anja Linstädter $^{38,39}$, Joan Llusià ${ }^{21}$, Marc Macias-Fauria ${ }^{40}$, Andrey V. Malyshev $^{8}$, Pille Mänd ${ }^{41}$, Miles Marshall ${ }^{42}$, Ashley M. Matheny ${ }^{43}$, Nate McDowell $^{44}$, Ina C. Meier ${ }^{45}$, Frederick C. Meinzer ${ }^{46}$, Sean T. Michaletz ${ }^{47,48,18}$, Megan L. Miller ${ }^{49}$, Lena Muffler ${ }^{8,45}$, Michal Oravec $^{27}$, Ivika Ostonen ${ }^{41}$, Albert Porcar-Castell ${ }^{50}$, Catherine Preece $^{20,21}$, lain C. Prentice ${ }^{51}$, Dajana Radujković ${ }^{22}$, Virve Ravolainen ${ }^{52}$, Relena Ribbons ${ }^{53}$, Jan C. Ruppert ${ }^{54}$, Lawren Sack ${ }^{55}$, Jordi Sardans ${ }^{20,21}$, Andreas Schindlbacher ${ }^{56}$, Christine Scoffoni ${ }^{57}$, Bjarni D. Sigurdsson ${ }^{4}$, Simon Smart ${ }^{58}$, Stuart W. Smith ${ }^{59,60}$, Fiona Soper $^{61}$, James D. M. Speed ${ }^{62}$, Anne Sverdrup-Thygeson ${ }^{10}$, Markus A. K. Sydenham ${ }^{63}$, Arezoo Taghizadeh-Toosi ${ }^{64}$, Richard J. Telford ${ }^{3}$, Katja Tielbörger ${ }^{54}$, Joachim P. Töpper ${ }^{65,66}$, Otmar Urban ${ }^{27}$, Martine van der Ploeg ${ }^{67}$, Leandro Van Langenhove ${ }^{22}$, Kristýna Večeřová ${ }^{27}$, Arne Ven ${ }^{22}$, Erik Verbruggen ${ }^{22}$, Unni Vik ${ }^{68}$, Robert Weigel ${ }^{45}$, Thomas Wohlgemuth ${ }^{36}$, Lauren K. Wood ${ }^{24}$, Julie Zinnert ${ }^{24}$, Kamal Zurba $^{69}$

Affiliations: ${ }^{1}$ Centre for Environmental and Marine Studies (CESAM), Department of Environment and Planning, University of Aveiro, Aveiro, Portugal; ${ }^{2} \mathrm{BC} 3$-Basque Centre for Climate Change, University of the Basque Country, Leioa, Spain; ${ }^{3}$ Department of Biological Sciences and Bjerknes Centre for Climate Research, University of Bergen, Bergen, Norway; ${ }^{4}$ Department of Natural Resources and Environmental Sciences, Agricultural University of Iceland, Reykjavík, Iceland; ${ }^{5}$ Centre for African Conservation Ecology, Nelson Mandela University, Port Elizabeth, South Africa; ${ }^{6}$ Environmental Sciences, Copernicus Institute of Sustainable Development, Utrecht University, Utrecht, the Netherlands; ${ }^{7}$ Department of Geosciences and Natural Resource Management, University of Copenhagen, Frederiksberg, Denmark; ${ }^{8}$ Experimental Plant Ecology, Institute of Botany and Landscape Ecology, University of Greifswald, Greifswald, Germany; ${ }^{9}$ Schmid College of Science and Technology, Chapman University, Orange, USA; ${ }^{10}$ Faculty of Environmental Sciences and Natural Resource Management, Norwegian University of Life Sciences, Ås, Norway; ${ }^{11}$ Norwegian Institute for Nature Research - NINA and FRAM - High North Research Centre for Climate and the Environment, Tromsø, Norway; ${ }^{12}$ Environmental Change Institute, School of Geography and the Environment, University of Oxford, Oxford, UK; ${ }^{13}$ School of Life
Sciences, Arizona State University, Tempe, USA; ${ }^{14}$ Department of Civil, Environmental, and Geodetic Engineering, OhioState University, USA; ${ }^{15}$ College of Science and Engineering, James Cook University, Cairns, Queensland, Australia; ${ }^{16}$ Meteorology Department, Poznań University of Life Sciences, Poznań, Poland; ${ }^{17}$ Centre for Ecology \& Hydrology, Environment Centre Wales, Bangor, UK; ${ }^{18}$ Earth and Environmental Sciences Division, Los Alamos National Laboratory, Los Alamos, USA; ${ }^{19}$ Swiss Federal Institute for Forest, Snow and Landscape Research (WSL), Birmensdorf, Switzerland; ${ }^{20} \mathrm{CREAF}$, Cerdanyola del Vallès, Spain; ${ }^{21}$ CSIC, Global Ecology Unit CREAFCSIC-UAB, Bellaterra, Spain; ${ }^{22}$ Centre of Excellence PLECO (Plants and Ecosystems), Biology Department, University of Antwerp, Wilrijk, Belgium; ${ }^{23}$ Department of Environmental Sciences, Western Norway University of Applied Sciences, Sogndal, Norway; ${ }^{24}$ Department of Biology, Virginia Commonwealth University, Richmond, USA; ${ }^{25}$ Department of Biology, University of North Carolina, Chapel Hill, USA; ${ }^{26}$ Department of Environmental Sciences - Botany, University of Basel, Basel, Switzerland; ${ }^{27}$ Global Change Research Institute, The Czech Academy of Sciences, Brno, Czech Republic; ${ }^{28}$ Warnell School of Forestry and Natural Resources, University of Georgia, Athens, USA; ${ }^{29}$ Department of Plants, Soils and Climate, Utah State University, Logan, USA; ${ }^{30}$ Department of Forest Ecology and Management, Swedish University of Agricultural Sciences, Umeå, Sweden; ${ }^{31}$ Faculty of AgriSciences, Mendel University in Brno, Brno, Czech Republic; ${ }^{32}$ The Science Library, University of Oslo, Norway; ${ }^{33}$ Institute of Ecology and Botany, MTA Centre for Ecological Research, Vácrátót, Hungary; ${ }^{34}$ Department of Renewable Resources, University of Alberta, Edmonton, Canada; ${ }^{35}$ Climate Impacts Research Centre, Department of Ecology and Environmental Science, Umeå University, Abisko, Sweden; ${ }^{36}$ Forest Dynamics, Swiss Federal Institute for Forest, Snow and Landscape Research WSL, Birmensdorf, Switzerland; ${ }^{37}$ Clinical Trial Unit Bern, Department of Clinical Research, University of Bern, Bern, Switzerland; ${ }^{38}$ Institute of Crop Science and Resource Conservation (INRES), University of Bonn, Bonn, Germany; ${ }^{39}$ Range Ecology and Management Group, Botanical Institute, University of Cologne, Cologne, Germany; ${ }^{40}$ School of Geography and the Environment, University of Oxford, Oxford, UK; ${ }^{41}$ Institute of Ecology and Earth Sciences, University of Tartu, Tartu, Estonia; ${ }^{42}$ Bangor University School of Natural Sciences, Bangor, UK; ${ }^{43}$ Department of Geological Sciences, Jackson School of Geosciences, The University of Texas at Austin, Austin, USA; ${ }^{44}$ Pacific Northwest National Laboratory, Richland, USA; ${ }^{45}$ Plant Ecology, Albrecht-von-Haller Institute for Plant Sciences, University of Goettingen, Goettingen, Germany; ${ }^{46}$ Pacific Northwest Research Station, USDA Forest Service, Corvallis, USA; ${ }^{47}$ Biosphere 2 and Department of Ecology \& Evolutionary Biology, University of Arizona, Tucson, USA; ${ }^{48}$ Department of Botany and Biodiversity Research Centre, University of British Columbia, Vancouver, Canada; ${ }^{49}$ College of Natural Resources, University of Idaho, Moscow, USA; ${ }^{50}$ Optics of Photosynthesis Laboratory, Institute for Atmospheric and Earth System Research/Forest Sciences, University of Helsinki, Helsinki, Finland; ${ }^{51}$ AXA Chair Programme in Biosphere and Climate Impacts, Department of Life Sciences, Imperial College London, 
Ascot, UK; ${ }^{52}$ Norwegian Polar Institute, Fram Centre, Tromsø, Norway; ${ }^{53}$ Biology and Geology Departments, Lawrence University, Appleton, USA; ${ }^{54}$ Institute of Evolution and Ecology, Plant Ecology Group, University of Tübingen, Tübingen, Germany; ${ }^{55}$ Department of Ecology and Evolutionary Biology, University of California Los Angeles, Los Angeles, USA; ${ }^{56}$ Department of Forest Ecology and Soils, Federal Research and Training Centre for Forests, Natural Hazards and Landscape, Vienna, Austria; ${ }^{57}$ Department of Biological Sciences, California State University, Los Angeles, Los Angeles, USA; ${ }^{58}$ Centre for Ecology \& Hydrology, Environment Centre Lancaster, Lancaster University, Lancaster, UK; ${ }^{59}$ Asian School of the Environment, Nanyang Technological University of Singapore, Singapore; ${ }^{60}$ Department of Biology, Norwegian University of Science and Technology, Trondheim, Norway; ${ }^{61}$ Department of
Ecology and Evolutionary Biology, Cornell University, Ithaca, USA; ${ }^{62}$ Department of Natural History, NTNU University Museum, Norwegian University of Science and Technology, Trondheim, Norway; ${ }^{63}$ Norwegian Institute for Nature Research, Oslo, Norway; ${ }^{64}$ Department of Agroecology, Aarhus University, Tjele, Denmark; ${ }^{65}$ Department of Biological Sciences, University of Bergen, Bergen, Norway; ${ }^{66}$ Norwegian Institute for Nature Research, Bergen, Norway; ${ }^{67}$ Soil Physics and Land Management, Wageningen University, Wageningen, the Netherlands; ${ }^{68}$ Section for Genetics and Evolutionary Biology (EVOGENE), Department of Biosciences, University of Oslo, Oslo, Norway; ${ }^{69}$ Interdisciplinary Environmental Research Centre, Technische Universität Bergakademie Freiberg, Germany. 